\title{
The Effects of Muscle Relaxation Exercise and Music Therapy before Drain Removal on Pain and Psychometric Variables
}

\author{
Dilek AYGINN ${ }^{1}$, Gülșah AKMAN ${ }^{2}$, Seçil Kılıç ${ }^{3}$, Demet Yılmaz ${ }^{4}$ \\ ${ }^{1}$ Sakarya University, Vocational School of Health Sciences, Assoc. Prof. \\ ${ }^{2}$ Sakarya University, Institute of Health Sciences, Postgraduate Student Düzce University Training and \\ Research Hospital, Nurse \\ ${ }^{3}$ Düzce University, Institute of Health Sciences, Postgraduate Student \\ ${ }^{4}$ Düzce University, Institute of Social Sciences, Postgraduate Student
}

\begin{abstract}
Summary
Background and aims: This study aims to investigate the effects of muscle relaxation exercise and music therapy applied before the drain removal operation on pain, vital signs, and psychometric variables.

Methods: This study was carried out with 90 volunteer patients (45 experiment, 45 control group) between May 2014 and November 2014. Data were collected using the Patient Identification Forms, the Visual Analogue Scale (VAS) and Vital Signs forms with the face-to-face interviews. For the control group, the VAS scores and vital signs were noted and evaluated 15 minutes before the drain removal, immediately after the drain removal and at 15 min. The Music (Rast Mode), which was selected 15 minutes before the operation was listened by the experiment group patients, while muscle relaxation exercise was instructed and performed.

Results: In the experimental group, 53.3\% were women, $61.4 \%$ were married and $28.9 \%$ were between 46 and 60 years of age. In the control group $62.2 \%$ were women, $82.2 \%$ were married and $33.3 \%$ were over 61 years of old. Compared to the control group, the VAS scores and systolic blood pressure increased immediately after the drain removed in the experiment group, falling below the initial value at $15 \mathrm{~min}$. In terms of the type of the drain used, the number, diastolic pressure, and pulse rate, no relationship was found between the two groups $(p>0.05)$.

Conclusion: During the removal of drains, nurses play an important role in the practice of nonpharmacological methods, and may prevent the unnecessary use of analgesics. Muscle relaxation exercises and music therapy should be applied prior to drain removal procedures, as effective non-pharmacological methods for pain control, and health personnel should have sufficient expertise regarding the importance of nonpharmacological methods in pain management.
\end{abstract}

Keywords: pain, muscle relaxation exercise, music therapy, psychometric variables.

\section{Introduction}

Although pain has been experienced by humans since the beginning of their existence, it is a problem that they find difficult to express verbally (Özcan 2000, Aslan and Özyalçın 2010). Pain, which has various definitions, is currently not only considered as a sign of a disease, but also as a subject in its own right (Akdovan 1999). The word pain comes from the Latin word poena (punishment, torment) (Aslan 2011). Sternbach (1968) defines pain as an abstract (subjective) concept and as a personal and specific sign of hurt, a noxious warning that indicates possible tissue damage, and a cover of wound trying to protect the organism from damage (Sternbach 1968, Howard and Thurber 1998). According to McCaffery, pain can be defined as, "whatever the experiencing person says it is, existing whenever the experiencing person says it does (https://en.wikipedia.org/wiki/Margo_ McCaffery).Pain is best defined by the person suffering from it" (Kocaman 1994, Luckmann and Sorenso 1996, Samaraee et al 2010). The prevailing definition of the term pain was made by the Taxonomy Committee of the International Association for the Study of Pain (IASP), as follows: "an unpleasant sensory and emotional experience associated with actual or potential tissue damage, or described in terms of such damage" (Merskey et al 1986, Aslan 2002).

The American Pain Association describes pain as the 'fifth vital sign', and notes that pain is an important part of patient care (Willens 2006). Pain theories (Primitive Theory, Specificity Theory, Pattern Theory and Gate-Control Theory) are considered to provide a conceptual framework for health professionals' studies related to pain and for the specific methods to help manage pain; they also help us understand the efficacies of non-pharmacological interventions in pain relief (Summers 2000; Sütekin 2005; Serpell 2006).

1. Pain is classified in various ways: according to its site, the type of tissue from which it originates, the type of sensation it creates, etiopathogenesis, time of onset and the mechanisms, it's classified as nociceptive, neuropathic, deafferentation, reactive and psychosomatic. Another classification is postoperative pain. Postoperative pain is an acute pathological pain starting with surgical trauma, decreasing gradually, and 
ceasing with tissue healing. Postoperative pain is the most commonly encountered surgical complication (Kirdemir and Özorak 2011). The factors leading to pain after a surgical intervention may be listed as follows: surgical intervention not accepted by the patient, the previous pain and surgical experiences, muscle degradation due to incision, extremely tight sutures, inappropriately placed tubes and drains, wound dehiscence, and changing the dressing (Erdinç and Yücel 1993, http://www.e-kutuphane.teb.org.tr. Date of Access: 01.11.2016, Bektaş 2005).

The following may be listed as reasons why drains are applied to patients during surgery, generally at the wound site, or sites near the wound, for prophylactic or therapeutic means: to prevent accumulation of air, and development of seroma, hematoma and surgical site infections, to evaluate drainage fluid, and to maintain abscess drainage (Browett et al 1978, Memon et al 2001, Cordosi et al 2006, Tsujinaka, Kawamura et al 2008, Durai and $\mathrm{Ng}$ 2010).

The drainage tubes are commonly used in plastic surgery, breast surgery (for blood and lymph drainage), thoracic drainage, pilonidal sinus surgery, pancreas surgery (for draining secretions), biliary surgery and thyroid surgery (Sullivan 2008). They are classified as silastic and rubber according to the types of materials used, and as open/closed, and active/passive, according to the purpose and location of the placement. In surgical patients, drains resulting in gentle suction, such as the Penrose drain, Hemovac drain and Jackson-Pratt drain, are generally preferred (Makama and Ameh 2008). Although drains play important roles in supporting wound healing, their use in surgical interventions is still a matter of debate (Pearl and Rayburn 2004). The use of drains can result in many complications, such as breaking, difficulty in drain removal (due to adhesion), pain, the spontaneous displacement of a drain, bleeding, infection, obstruction and perforation (Gengross and Engler 1989, Maddox et al 2005, Chen, Li, Lix and Xul 2005). Following placement, drainage tubes become attached to the tissue in which they've been placed by applying negative pressure, especially by the application of a vacuum. herefore pulling with force during removal leads to a transient, acute pain (Sondak and Mortan 1985, Tzarnas 2006). The drain removal procedure causes the patient to feel anxiety and pain (Gift, Bolgiano and Cunningham 1991). In a prospective study conducted with 80 women, a significant correlation was detected between pain and the application of drain removal, and it has been remarked that it would be essential to identify the factors that lead to high pain scores during drain removal procedures (Mahfouz et al 2011).

It is still a matter of debate as to whether drain usage decreases pain and many studies have reported that the routine application of drainage decreased pain (Arslan et al. 2012). Controversial results have been obtained in some other studies, reporting that drain usage affected the patients' comfort negatively by increasing sensation of pain (Schoretsanitis et al 1998).

Pain management is important during diagnostic and therapeutic interventions and patient care, since effective pain management results in the early mobilization of the patient, shortens the duration of hospitalization, increases the patient's satisfaction, and decreases therapeutic costs (Watcha et al. 2003, de BeerJde et al. 2005 ). With drain removal it's important to control pain relating to drainage tube, especially when it develops during the removal procedure. It is therefore suggested that analgesic agents are used prior to the removal of the drain and these agents are currently being used in clinical practice (Walker 2007, Durai, Mouwnah and $\mathrm{Ng}$ 2009). It has also been suggested that the patient is told before the drainage tube is removed (Proof Level C), and pain is controlled using a pharmacological approach (Apfelbaum et al. 2003). The pain that occurs while the drain is present and during its removal has been evaluated as postoperative pain. For effective postoperative pain management, pain has to be followed-up in the same way as the hemodynamic signs. In an anesthesiology Intensive Care (IC) Unit or Arousal Unit (AU), the patient has to be evaluated for pain once every 15 minutes during the first hour, and once every one or two hours thereafter. Following the stay in IC Unit or AU, pain has to be evaluated once every four to eight hours. The appropriate evaluation of postoperative pain and effective pain management decrease the risk of postoperative complications developing (Proof Level B) (http://www.guideline.gov/content.aspx?id=23897. Date Accessed: 01.12.2016).

Both pharmacological and non-pharmacological methods are used in the treatment of pain. The World Health Organization recommends the Ladder System for the appropriate and successful treatment of pain (ref?). The first step for mild pain: the treatment is started with a non-opioid medication, which is a non-steroidal antiinflammatory drug. If the pain intensity increases unremittingly, the second step is applied, and a mild opioid analgesic is added to treatment. If pain relief is not provided and the pain intensity increases, a potent opioid analgesic is added to treatment as the third step (World Health Organization Cancer Pain Relief. Geneva: 1986, Erdine 2003). Non-pharmacological methods are as follows: cognitive-behavioral methods (muscle relaxation, distraction, respiratory exercises, imagination, listening to music), biological feed-back, acupuncture, meditation, hypnosis, coping with stress, and dermal stimulation (massage, transcutaneous electrical stimulation, dermal application of menthol) (Pittler and Ernst 2008, Bennett, Bagnall and José Closs 2009, Walsh et al 2009, Bradt and Dileo 2010, Paley et al 2011). The muscle relaxation technique, a non-pharmacological method, was first defined by Jacobson and introduced to the science by Herbert Benson. In this method, pain is decreased by distracting the patient's attention to another point other than the pain, causing an increase in the 
release of endorphins. It can be used for both acute and chronic pain. The therapeutic effect of music therapy has been known since ancient times (Bonica 1990 ,Özveren 2011).

Accordingly, this study has been planned and conducted on the basis that in addition to pharmacological methods, non-pharmacological ones may also be effective in controlling the pain that develops during the removal of drainage tubes, and the unnecessary use of analgesic usage in surgery clinics can be avoided.

\section{Rationale Of The Study}

Nurses play an important role in the application of non-pharmacological methods during drainage tube removal and with the application of these methods the unnecessary use of analgesics can be avoided. This also contributes to the development/progression of independent applications by nurses.

\section{Objective Of The Study}

This study was conducted to investigate the effect of muscle relaxation exercises and music therapy applied prior to the painful procedure of drain removal, for patients who were hospitalized and applied drainage tubes at the General Surgery Clinic of the Düzce University Training and Health Application Hospital and by evaluating the impact of these non-pharmacological applications on pain and psychometric variables.

\section{Hypothesis Of The Study}

$\mathbf{H}_{0}$ The muscle relaxation exercise and music therapy applied prior to drain removal has no effect on pain.

$\mathbf{H}_{0}$ The muscle relaxation exercise and music therapy applied prior to drain removal has no effect on psychometric variables.

$\mathbf{H}_{1}$ The muscle relaxation exercise and music therapy applied prior to drain removal has an effect on pain.

$\mathbf{H}_{1}$ The muscle relaxation exercise and music therapy applied prior to drain removal has an effect on psychometric variables.

\section{Materials And Methods}

This research was planned as a randomized single blind and controlled experimental study. It was conducted at the General Surgery Clinic of the Düzce University Training and Research Hospital, between May and November 2014.

The universe of the study consisted of all patients who had been hospitalized at the General Surgery Clinic of the Düzce University Training and Research Hospital between the dates during which the study was performed, and who had drainage tubes inserted for any reason. The sampling of the study was identified using the non-probability sampling method, and included the patients who were admitted to the General Surgery Clinic during the period of data collection and who had drains inserted for any reason; the patient volunteers who were capable of speaking and understanding Turkish, were 18 years of age or older, oriented to place and time, not existing with visual or hearing loss and not presenting any psychiatric disorder participated in the study. The study was completed with a total of 90 patients; of these, 45 were case studies and 45 were control subjects (control and case study groups were selected by tossing a coin).

The data were collected using face-to-face interviews and the Patient Information Form (20 questions) developed by the researcher according to the information in the literature, the Visual Analog Scale (VAS) for evaluating pain intensity, and the Vital Signs Form for psychometric evaluation. The duration of the questionnaire application was about 50 minutes.

Arterial blood pressure, heart rate, respiratory rate and body temperature values were recorded on the vital signs form 15 minutes before drain removal, immediately after the drain removal, and at $15 \mathrm{~min}$.

The visual Pain Scale (VPS), developed by Price et al. (1983) for evaluating the levels of pain, is used to measure the patient's pain intensity. It is a $10-\mathrm{cm}$ rule, indicating analgesia level on its left extremity, and the most severe level of pain that can be experienced (unbearable pain) on its right extremity. On this continuum, the patient marks the value that corresponds to the pain he or she is feeling. The numerical value calculated indicates the intensity of the patient's pain. The level of pain and vital signs in the control group were evaluated and recorded 15 minutes before drain removal, immediately after the drain removal, and at 15 minutes, using the VPS for pain intensity. The patients in case study group, unlike the control subjects, has been taught how to use a muscle relaxation exercise and were asked to perform it while listening to a selected piece of music, 15 minutes before the application. The pain level and vital signs were similarly recorded immediately after the drain removal and 15 minutes after the application, using the VPS for pain. Since the number of patients is high in general surgery clinic, the study participants listened to the music using headphones and an MP3 player, in order not to disturb the other patients. The type of music chosen was as a result of an investigation made of the literature. We selected a soft instrumental musical theme (Rast mode), and requested the patients to listen to it for $20 \mathrm{~min}$ (Özveren 2011, Çiftci 2011). 
The consent of the ethical committee and permission from the institution at which the research would be conducted were taken prior to study. The nature of the research was explained to the patients and only those who volunteered were included in the study.

Statistical analysis was performed using the SPSS v20.0 software (SPSS Inc., Chicago, IL, USA). Descriptive data were expressed in frequency, arithmetical mean, standard deviation and percentage. Independent comparisons were made using the non-parametric Mann-Whitney U and Kruskal-Wallis tests; the non-parametric Friedman test was used for dependent analyses. The Chi-square test was used for cross-match comparisons. A $p<0.05$ value of was considered statistically significant.

\section{Results}

The sociodemographic characteristics of the patients are expressed in Table 1. Educational levels and place of residence differed significantly between the case and control groups. The number of high-school and upper grade graduates and city dwellers were higher in the case group $(p<0.05)$ (Table 1$)$.

Table 1. Comparison of the sociodemographic characteristics

\begin{tabular}{|c|c|c|c|c|c|c|c|c|}
\hline & \multicolumn{2}{|c|}{ Case } & \multicolumn{2}{|c|}{ Control } & \multicolumn{2}{|c|}{ Total } & \multirow[b]{2}{*}{$\chi^{2}$} & \multirow[b]{2}{*}{$\mathrm{p}^{\mathrm{a}}$} \\
\hline Sex & $\mathrm{N}$ & $\%$ & $\mathrm{~N}$ & $\%$ & $\mathrm{n}$ & $\%$ & & \\
\hline Female & 24 & 53,3 & 28 & 62,2 & 52 & 57,8 & \multirow{2}{*}{0,729} & \multirow{2}{*}{0,393} \\
\hline Male & 21 & 46,7 & 17 & 37,8 & 38 & 42,2 & & \\
\hline Marital Status & $\mathrm{N}$ & $\%$ & $\mathrm{~N}$ & $\%$ & $\mathrm{n}$ & $\%$ & $\chi^{2}$ & $\mathrm{p}^{\mathrm{a}}$ \\
\hline Single & 9 & $20,0 \%$ & 3 & $6,7 \%$ & 12 & $13,3 \%$ & \multirow{3}{*}{4,303} & \multirow{3}{*}{0,116} \\
\hline Married & 29 & $64,4 \%$ & 37 & $82,2 \%$ & 66 & $73,3 \%$ & & \\
\hline Divorced & 7 & $15,6 \%$ & 5 & $11,1 \%$ & 12 & $13,3 \%$ & & \\
\hline Educational Status & $\mathrm{N}$ & $\%$ & $\mathrm{~N}$ & $\%$ & $\mathrm{~N}$ & $\%$ & $\chi^{2}$ & $\mathrm{p}^{\mathrm{a}}$ \\
\hline Illiterate & 2 & $4,4 \%$ & 10 & $22,2 \%$ & 12 & $13,3 \%$ & \multirow{5}{*}{13,098} & \multirow{5}{*}{$0,011^{*}$} \\
\hline Literate & 13 & $28,9 \%$ & 6 & $13,3 \%$ & 19 & $21,1 \%$ & & \\
\hline Elementary education & 11 & $24,4 \%$ & 19 & $42,2 \%$ & 30 & $33,3 \%$ & & \\
\hline High-school & 15 & $33,3 \%$ & 7 & $15,6 \%$ & 22 & $24,4 \%$ & & \\
\hline Higher education & 4 & $8,9 \%$ & 3 & $6,7 \%$ & 7 & $7,8 \%$ & & \\
\hline Living place & $\mathrm{N}$ & $\%$ & $\mathrm{~N}$ & $\%$ & $\mathrm{~N}$ & $\%$ & $\chi^{2}$ & $\mathrm{p}^{\mathrm{a}}$ \\
\hline Rural & 8 & $17,8 \%$ & 21 & $46,7 \%$ & 29 & $32,2 \%$ & \multirow{2}{*}{8,598} & \multirow{2}{*}{$0,003 * *$} \\
\hline Urban & 37 & $82,2 \%$ & 24 & $53,3 \%$ & 61 & $67,8 \%$ & & \\
\hline Age & $\mathrm{N}$ & $\%$ & $\mathrm{~N}$ & $\%$ & $\mathrm{~N}$ & $\%$ & $\chi^{2}$ & $\mathrm{p}^{\mathrm{a}}$ \\
\hline $15-30$ years & 8 & $17,8 \%$ & 4 & $8,9 \%$ & 12 & $13,3 \%$ & \multirow{4}{*}{839,0} & \multirow{4}{*}{0,161} \\
\hline $31-45$ years & 12 & $26,7 \%$ & 14 & $31,1 \%$ & 26 & $28,9 \%$ & & \\
\hline $46-60$ years & 13 & $28,9 \%$ & 12 & $26,7 \%$ & 25 & $27,8 \%$ & & \\
\hline 61 years and above & 12 & $26,7 \%$ & 15 & $33,3 \%$ & 27 & $30,0 \%$ & & \\
\hline Number of children & $\mathrm{N}$ & $\%$ & $\mathrm{~N}$ & $\%$ & $\mathrm{~N}$ & $\%$ & $\chi^{2}$ & $\mathrm{p}^{\mathrm{a}}$ \\
\hline None & 8 & $17,8 \%$ & 4 & $8,9 \%$ & 12 & $13,3 \%$ & \multirow{5}{*}{8} & \multirow{5}{*}{$17,8 \%$} \\
\hline 2 children & 8 & $17,8 \%$ & 10 & $22,2 \%$ & 18 & $20,0 \%$ & & \\
\hline 3 children & 14 & $31,1 \%$ & 14 & $31,1 \%$ & 28 & $31,1 \%$ & & \\
\hline $4 * 5$ children & 10 & $22,2 \%$ & 7 & $15,6 \%$ & 17 & $13,3 \%$ & & \\
\hline 6 and more & 5 & $11,1 \%$ & 10 & $22,2 \%$ & 15 & $12,2 \%$ & & \\
\hline Income & $\mathrm{N}$ & $\%$ & $\mathrm{~N}$ & $\%$ & $\mathrm{~N}$ & $\%$ & $\chi^{2}$ & $\mathrm{p}^{\mathrm{a}}$ \\
\hline Income less than expenses & 23 & $51,1 \%$ & 16 & $35,6 \%$ & 39 & $43,3 \%$ & \multirow[t]{3}{*}{-} & \multirow[t]{3}{*}{ - } \\
\hline $\begin{array}{l}\text { Equity of income and } \\
\text { outgoings }\end{array}$ & 22 & $48,9 \%$ & 26 & $57,8 \%$ & 48 & $53,3 \%$ & & \\
\hline Income more than outgoings & 0 & $0,0 \%$ & 3 & $6,7 \%$ & 3 & $3,3 \%$ & & \\
\hline Occupation & $\mathrm{N}$ & $\%$ & $\mathrm{~N}$ & $\%$ & $\mathrm{~N}$ & $\%$ & $\chi^{2}$ & $\mathrm{p}^{\mathrm{a}}$ \\
\hline Housewife & 19 & $42,2 \%$ & 24 & $53,3 \%$ & 43 & $47,8 \%$ & \multirow[t]{6}{*}{-} & \multirow[t]{6}{*}{-} \\
\hline Official & 2 & $4,4 \%$ & 3 & $6,7 \%$ & 5 & $5,6 \%$ & & \\
\hline Worker & 5 & $11,1 \%$ & 5 & $11,1 \%$ & 10 & $11,1 \%$ & & \\
\hline Retired & 8 & $17,8 \%$ & 7 & $15,6 \%$ & 15 & $16,7 \%$ & & \\
\hline Self-employment & 6 & $13,3 \%$ & 6 & $13,3 \%$ & 12 & $13,3 \%$ & & \\
\hline Others & 5 & $11,1 \%$ & 0 & $0,0 \%$ & 5 & $5,6 \%$ & & \\
\hline Total & 45 & $100,0 \%$ & 45 & $100,0 \%$ & 90 & $\begin{array}{c}100,0 \\
\%\end{array}$ & & \\
\hline
\end{tabular}


a. Chi-square test, b. Mann-Whitney U test $* * \mathrm{p}<0,05, * \mathrm{p}<0,01$

The results of Chi-square test revealed no difference between the case $(35.6 \%)$ and control $(37.8 \%)$ groups in terms of smoking habits $(\mathrm{p}>0.05)$. There was no correlation between attempts to cope with pain between the case and control subjects ( $p>0.05)$; however, the rate of analgesic use was found to be significantly higher in the control group $(\mathrm{p}<0.01)$.

Comparisons of the time of drain placement, and the number, type and location of the drains, between the case and control groups, are shown in the table below (Table 2). Most of the patients (20\%) were diagnosed with multinodular goiter. It was established that the inserted drains were maintained for approximately three days. A minivac drain was inserted in $45.6 \%$ and a single drain was used in $95.6 \%$ of the patients, and the location of the drain was in the lower right quadrant in $27.8 \%$ of the volunteers (Table 2). The results of MannWhitney $U$ test and Chi-square test revealed no significant differences between the two groups in terms of the time of drain placement, and the number and type of drains used ( $>>0.05)$ (Table 2).

Table 2. Comparisons of the time of drain placement, and the number, type and location of drains

\begin{tabular}{|c|c|c|c|c|c|c|c|c|}
\hline & Cas & & Col & & Tot & & & \\
\hline Time of drain placement & $\mathrm{N}$ & $\%$ & $\mathrm{~N}$ & $\%$ & $\mathrm{n}$ & $\%$ & $\mathrm{U}$ & $\mathrm{p}^{\mathrm{b}}$ \\
\hline 2 days previously & 8 & $17,8 \%$ & 10 & $22,2 \%$ & 18 & $20,0 \%$ & \multirow{5}{*}{861,5} & \multirow{5}{*}{0,212} \\
\hline 3 days previously & 13 & $28,9 \%$ & 15 & $33,3 \%$ & 28 & $31,1 \%$ & & \\
\hline 4 days previously & 5 & $11,1 \%$ & 10 & $22,2 \%$ & 15 & $16,7 \%$ & & \\
\hline 5 days previously & 9 & $20,0 \%$ & 4 & $8,9 \%$ & 13 & $14,4 \%$ & & \\
\hline More than 6 days previously & 10 & $22,2 \%$ & 6 & $13,3 \%$ & 16 & $2,2 \%$ & & \\
\hline Number of drains & $\mathrm{N}$ & $\%$ & $\mathrm{~N}$ & $\%$ & $\mathrm{n}$ & $\%$ & $\mathrm{U}$ & $\mathrm{p}^{\mathrm{b}}$ \\
\hline 1 & 44 & $97,8 \%$ & 42 & $93,3 \%$ & 86 & $95,6 \%$ & \multirow{3}{*}{967,0} & \multirow{3}{*}{0,304} \\
\hline 2 & 1 & $2,2 \%$ & 2 & $4,4 \%$ & 3 & $3,3 \%$ & & \\
\hline 3 & 0 & $0,0 \%$ & 1 & $2,2 \%$ & 1 & $1,1 \%$ & & \\
\hline Type of drain & $\mathrm{N}$ & $\%$ & $\mathrm{~N}$ & $\%$ & $\mathrm{n}$ & $\%$ & $\mathrm{U}$ & $\mathrm{p}^{\mathrm{b}}$ \\
\hline Free & 21 & $46,7 \%$ & 16 & $35,6 \%$ & 37 & $41,1 \%$ & \multirow{3}{*}{3,985} & \multirow{3}{*}{0,136} \\
\hline Minivac & 16 & $35,6 \%$ & 25 & $55,6 \%$ & 41 & $45,6 \%$ & & \\
\hline Hemovac & 8 & $17,8 \%$ & 4 & $8,9 \%$ & 12 & $13,3 \%$ & & \\
\hline Location of drain & $\mathrm{N}$ & $\%$ & $\mathrm{~N}$ & $\%$ & $\mathrm{n}$ & $\%$ & $\mathrm{U}$ & $\mathrm{p}^{\mathrm{b}}$ \\
\hline Upper right quadrant & 6 & $13,3 \%$ & 5 & $11,1 \%$ & 11 & $12,2 \%$ & \multirow[t]{9}{*}{-} & \multirow[t]{9}{*}{-} \\
\hline Lower right quadrant & 13 & $28,9 \%$ & 12 & $26,7 \%$ & 25 & $27,8 \%$ & & \\
\hline Upper left quadrant & 2 & $4,4 \%$ & 3 & $6,7 \%$ & 5 & $5,6 \%$ & & \\
\hline Lower left quadrant & 8 & $17,8 \%$ & 8 & $17,8 \%$ & 16 & $17,8 \%$ & & \\
\hline Cervical region & 7 & $15,6 \%$ & 11 & $24,4 \%$ & 18 & $20,0 \%$ & & \\
\hline Right axillary & 3 & $6,7 \%$ & 3 & $6,7 \%$ & 6 & $6,7 \%$ & & \\
\hline Left axillary & 1 & $2,2 \%$ & 2 & $4,4 \%$ & 3 & $3,3 \%$ & & \\
\hline Coccyx & 4 & $8,9 \%$ & 1 & $2,2 \%$ & 5 & $5,6 \%$ & & \\
\hline Anal region & 1 & $2,2 \%$ & 0 & $0,0 \%$ & 1 & $1,1 \%$ & & \\
\hline Total & 45 & $100,0 \%$ & 45 & $\begin{array}{c}100,0 \\
\%\end{array}$ & 90 & $\begin{array}{c}100,0 \\
\%\end{array}$ & & \\
\hline
\end{tabular}

a. Chi-square test, b. Mann-Whitney U test,

Table 3. Comparison of the VPS (pain) data between the case and control groups

\begin{tabular}{|c|c|c|c|c|c|c|c|c|}
\hline & \multicolumn{2}{|l|}{ VPS Value } & n & Mean \pm SD & Min.*Max. & Median & $\mathbf{U}$ & $p^{a}$ \\
\hline \multirow{6}{*}{ 恶 } & \multirow{2}{*}{$\begin{array}{l}15 \text { min } \\
\text { before }\end{array}$} & Case & 45 & $4,16 \pm 1,313$ & $0 * 7$ & 4,0 & \multirow{2}{*}{562,0} & \multirow{2}{*}{$0,000 * *$} \\
\hline & & Control & 45 & $2,76 \pm 1,873$ & $0 * 8$ & 3,0 & & \\
\hline & \multirow{2}{*}{$\begin{array}{l}\text { immediately } \\
\text { after }\end{array}$} & Case & 45 & $1,91 \pm 1,240$ & $0 * 5$ & 2,0 & \multirow{2}{*}{350,0} & \multirow{2}{*}{$0,000 * *$} \\
\hline & & Control & 45 & $3,84 \pm 1,692$ & $0 * 8$ & 4,0 & & \\
\hline & \multirow[t]{2}{*}{ at $15 \mathrm{~min}$} & Case & 45 & $0,89 \pm 1,005$ & $0 * 5$ & 1,0 & \multirow{2}{*}{210,0} & \multirow{2}{*}{$0,000 * *$} \\
\hline & & Control & 45 & $2,80 \pm 1,408$ & $1 * 7$ & 3,0 & & \\
\hline & $\begin{array}{l}\text { a. Mann-W } \\
* * \mathrm{p}<0,001\end{array}$ & ney $\quad U$ & test & & & & & \\
\hline
\end{tabular}




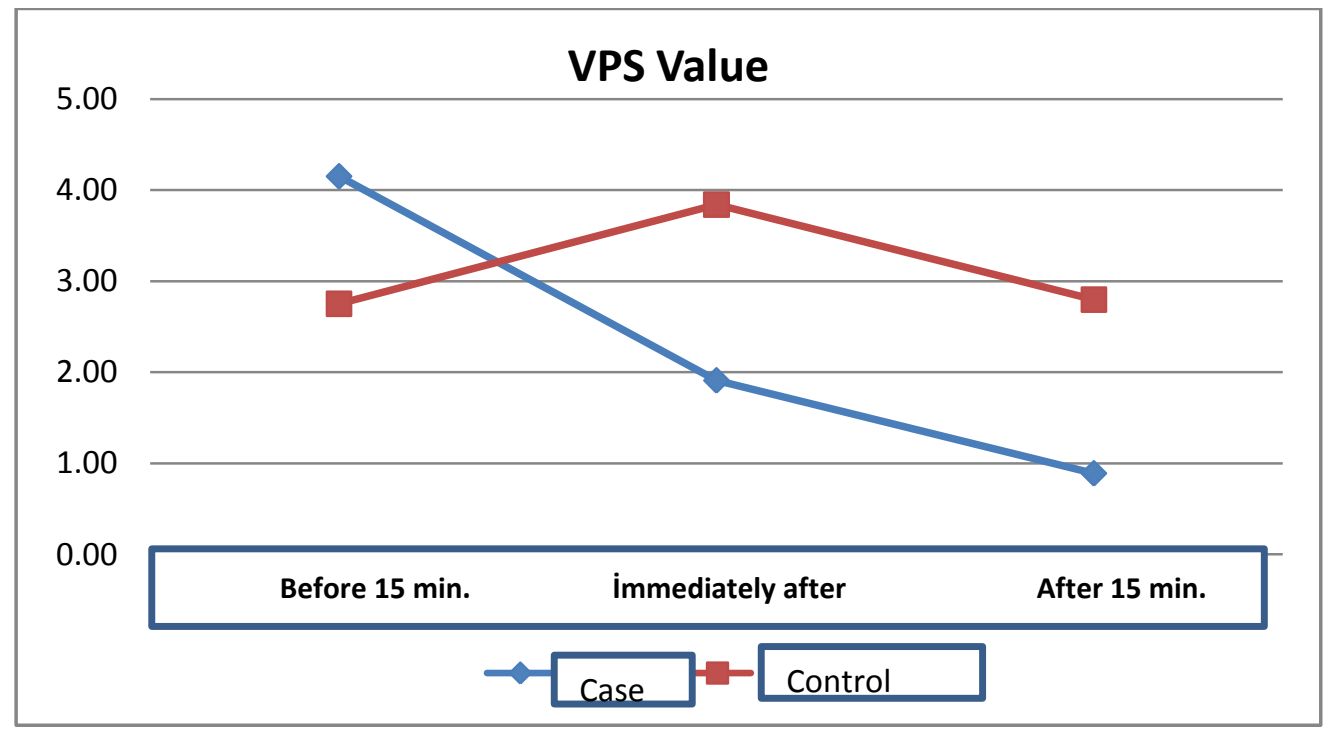

Figure 1. Mean VPS values determined in case and control groups

Comparisons of the VPS scores between the volunteer patients who were given exercise and music therapy for pain relief and the control subjects, who did not receive these treatments, are given in Table 3 and indicate the values obtained 15 minutes prior to drain removal, immediately after the drain removal, and 15 minutes following the procedure. These results revealed that the mean VPS score determined 15 minutes prior to the procedure was significantly higher in the case group patients $(p<0.001)$; whereas, the mean VPS score determined 15 minutes following the procedure was significantly lower in the case group $(\mathrm{p}<0.001)$. In the control group, the VPS score, which increased immediately after the drain removal, returned to its initial level 15 minutes following drain removal; whereas, it reduced to further below the initial value in the case group (Table 3).

The mean values of the VPS pain scores assessed 15 minutes prior to drain removal, immediately after the drain removal and 15 minutes after the procedure did not differ significantly in the case and control groups, when they were evaluated in terms of age $(p>0.05)$. When the VPS (pain) scores were evaluated in terms of gender; the value of VPS score determined 15 minutes before the procedure differed regarding gender in the control group $(\mathrm{p}<0.05)$, and was found to be higher in women. No statistically significant differences were determined in terms of chronic diseases. When the VPS values were evaluated in terms of attempting to cope with pain; the VPS value determined 15 minutes before the procedure was significantly higher in the patients not attempting to cope with the pain, only in the control group $(\mathrm{p}<0.05)$.

\section{Evaluation of the Results Related to Psychometric Variables of the Patients}

Table 4. Comparison of the data relating to pulse, respiration and blood pressure in the case and control groups

\begin{tabular}{|c|c|c|c|c|c|c|c|c|}
\hline & Pulse & & $\mathbf{n}$ & Mean \pm SD & Min.*Max. & Median & $\mathbf{U}$ & $p^{a}$ \\
\hline \multirow{6}{*}{ 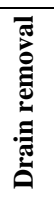 } & \multirow[t]{2}{*}{$15 \mathrm{~min}$ before } & Case & 45 & $79,07 \pm 13,167$ & $62 * 128$ & 76,0 & \multirow{2}{*}{909,0} & \multirow{2}{*}{0,402} \\
\hline & & Control & 45 & $82,40 \pm 15,928$ & $60 * 121$ & 80,0 & & \\
\hline & \multirow{2}{*}{$\begin{array}{l}\text { Immediately } \\
\text { after }\end{array}$} & Case & 45 & $85,56 \pm 12,120$ & $70 * 132$ & 82,0 & \multirow{2}{*}{958,5} & \multirow{2}{*}{0,662} \\
\hline & & Control & 45 & $83,67 \pm 16,110$ & $58 * 120$ & 82,0 & & \\
\hline & \multirow[t]{2}{*}{$15 \mathrm{~min}$ after } & Case & 45 & $78,82 \pm 10,949$ & $62 * 120$ & 76,0 & \multirow{2}{*}{821,5} & \multirow{2}{*}{0,122} \\
\hline & & Control & 45 & $82,98 \pm 14,260$ & $60 * 111$ & 82,0 & & \\
\hline & \multicolumn{2}{|c|}{ Respiratory rate } & $\mathbf{n}$ & Mean \pm SD & Min.*Max. & Median & $\mathbf{U}$ & $\mathbf{p}^{\mathbf{a}}$ \\
\hline \multirow{6}{*}{ 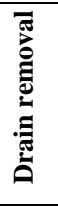 } & \multirow[t]{2}{*}{15 min before } & Case & 45 & $20,67 \pm 2,663$ & $18 * 28$ & 20,0 & \multirow{2}{*}{696,0} & \multirow{2}{*}{$0,008^{* *}$} \\
\hline & & Control & 45 & $22,09 \pm 2,695$ & $18 * 28$ & 22,0 & & \\
\hline & \multirow{2}{*}{$\begin{array}{l}\text { Immediately } \\
\text { after }\end{array}$} & Case & 45 & $23,60 \pm 2,240$ & $18 * 32$ & 24,0 & \multirow{2}{*}{$\begin{array}{c}1010 \\
5\end{array}$} & \multirow{2}{*}{0,986} \\
\hline & & Control & 45 & $23,69 \pm 2,372$ & $20 * 30$ & 24,0 & & \\
\hline & \multirow[t]{2}{*}{15 min after } & Case & 45 & $21,33 \pm 2,449$ & $18 * 30$ & 22,0 & \multirow{2}{*}{596,5} & \multirow{2}{*}{$0,000 * *$} \\
\hline & & Control & 45 & $22,89 \pm 1,837$ & $18 * 28$ & 24,0 & & \\
\hline & \multicolumn{2}{|c|}{ Systolic blood pressure } & $\mathbf{n}$ & Mean \pm SD & Min.*Max. & Median & $\mathbf{U}$ & $\mathbf{p}^{\mathbf{a}}$ \\
\hline \multirow{7}{*}{ 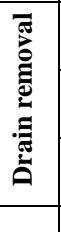 } & \multirow[t]{2}{*}{15 min before } & Case & 45 & $123,33 \pm 17,189$ & $100 * 150$ & 130,0 & \multirow{2}{*}{993,0} & \multirow{2}{*}{0,873} \\
\hline & & Control & 45 & $122,89 \pm 17,271$ & $100 * 150$ & 120,0 & & \\
\hline & \multirow{2}{*}{$\begin{array}{l}\text { Immediately } \\
\text { after }\end{array}$} & Case & 45 & $128,00 \pm 14,554$ & $100 * 150$ & 130,0 & \multirow{2}{*}{982,5} & \multirow{2}{*}{0,805} \\
\hline & & Control & 45 & $128,44 \pm 14,609$ & $100 * 150$ & 130,0 & & \\
\hline & \multirow[t]{2}{*}{15 min after } & Case & 45 & $119,11 \pm 15,199$ & $100 * 150$ & 120,0 & \multirow{2}{*}{685,5} & \multirow{2}{*}{$0,007^{* *}$} \\
\hline & & Control & 45 & $128,67 \pm 16,597$ & $100 * 150$ & 130,0 & & \\
\hline & \multicolumn{2}{|c|}{ Diastolic blood pressure } & $\mathbf{n}$ & Mean \pm SD & Min.*Max. & Median & $\mathbf{U}$ & $\mathbf{p}^{\mathbf{a}}$ \\
\hline 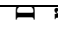 & $15 \mathrm{~min}$ before & Case & 45 & $71,56 \pm 8,516$ & $60 * 90$ & 70,0 & 816,0 & 0,090 \\
\hline
\end{tabular}


The Effects of Muscle Relaxation Exercise and Music Therapy before Drain Removal on Pain and

\begin{tabular}{|c|c|c|c|c|c|c|c|}
\hline & Control & 45 & $74,44 \pm 8,134$ & $60 * 90$ & 70,0 & & \\
\hline \multirow{2}{*}{$\begin{array}{l}\text { Immediately } \\
\text { after }\end{array}$} & Case & 45 & $74,67 \pm 7,261$ & $60 * 90$ & 70,0 & \multirow{2}{*}{659,5} & \multirow{2}{*}{$0,002^{* *}$} \\
\hline & Control & 45 & $79,33 \pm 7,198$ & $60 * 90$ & 80,0 & & \\
\hline \multirow[t]{2}{*}{15 min after } & Case & 45 & $72,22 \pm 6,704$ & $60 * 90$ & 70,0 & \multirow{2}{*}{697,0} & \multirow{2}{*}{$0,005^{* *}$} \\
\hline & Control & 45 & $76,67 \pm 7,687$ & $60 * 90$ & 80,0 & & \\
\hline \multicolumn{3}{|c|}{ a. Mann-Whitney U test } & $* * \mathrm{p}<0,05$ & & & & \\
\hline
\end{tabular}

Table 4 indicates the mean, standard deviation, minimum, maximum and median values, and the Mann-Whitney U test results in the case and control groups, relating to pulse, respiration and blood pressure data assessed 15 minutes before drain removal, immediately after the drain removal and 15 minutes after the procedure. In none of these assessment stages did pulse data differ between the case and control groups $(p>0.05)$. When the data relating to respiration were evaluated, the mean respiratory rates determined 15 minutes before and 15 minutes following the procedure were found to be significantly lower in the case group $(\mathrm{p}<0.01)$; however, the respiratory rate determined immediately after the procedure did not differ between groups ( $>0.05$ ). The mean values of systolic blood pressure assessed 15 minutes prior to drain removal and immediately after this procedure did not show any differences between the groups, while the systolic blood pressure measured 15 minutes after the procedure was significantly lower in the case group patients compared to the control group $(\mathrm{p}<0.01)$. Diastolic blood pressure measured 15 minutes before the procedure did not differ significantly between the groups, while the diastolic blood pressure values detected immediately after the drain removal and 15 minutes following this procedure were found to be significantly lower in the case group patients, compared to the control group $(\mathrm{p}<0.01)$.

Table 5. Comparison of data relating to body temperature in case and control groups

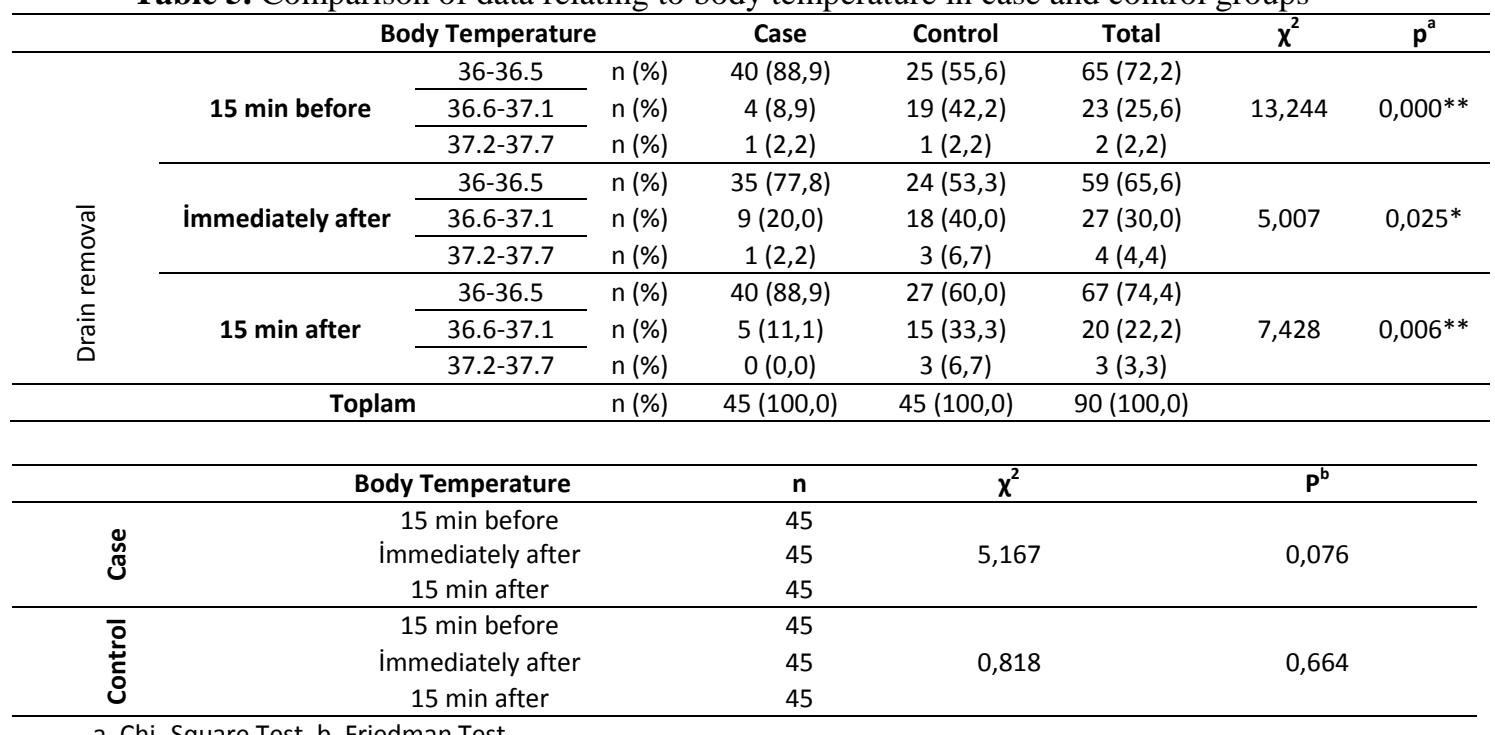

a. Chi- Square Test, b. Friedman Test

The body temperature values measured 15 minutes prior to drain removal, just after the drain removal and 15 minutes following this procedure were significantly lower in the case group patients than those of the control group $(p<0.01 ; p<0.05)$ (data of the 37.2-37.7 group was not sufficient and it was therefore excluded from the Chi-square analysis) (Table 5). In the case and control groups, the results of the Friedman test revealed no significant differences between the body temperature values measured 15 minutes before drain removal, immediately after the drain removal and 15 minutes following this procedure $(\mathrm{p}>0.05)$.

Table 6. Comparisons of data relating to pulse, respiration and blood pressure evaluated 15 minutes prior to drain removal, just after the drain removal and 15 minutes following this procedure

\begin{tabular}{|c|c|c|c|c|c|c|c|}
\hline \multicolumn{2}{|c|}{ Pulse } & $\mathrm{N}$ & Mean \pm SD & Min.*Max. & Median & $\chi^{2}$ & $\mathrm{p}^{\mathrm{a}}$ \\
\hline \multirow{3}{*}{ שू } & 15 min before & 45 & $79,07 \pm 13,167$ & $62 * 128$ & 76,0 & \multirow{3}{*}{30,742} & \multirow{3}{*}{$0,000 * *$} \\
\hline & Immediately after & 45 & $85,56 \pm 12,120$ & $70 * 132$ & 82,0 & & \\
\hline & 15 min after & 45 & $78,82 \pm 10,949$ & $62 * 120$ & 76,0 & & \\
\hline \multirow{3}{*}{$\begin{array}{l}\overline{\dot{E}} \\
\dot{\Xi}\end{array}$} & 15 min before & 45 & $82,40 \pm 15,928$ & $60 * 121$ & 80,0 & \multirow{3}{*}{2,687} & \multirow{3}{*}{0,261} \\
\hline & Immediately after & 45 & $83,67 \pm 16,110$ & $58 * 120$ & 82,0 & & \\
\hline & 15 min after & 45 & $82,98 \pm 14,260$ & $60 * 111$ & 82,0 & & \\
\hline \multicolumn{2}{|c|}{ Respiratory rate } & $\mathrm{n}$ & Mean \pm SD & Min.*Max. & Median & $\chi^{2}$ & $\mathrm{p}^{\mathrm{a}}$ \\
\hline
\end{tabular}




\begin{tabular}{|c|c|c|c|c|c|c|c|}
\hline \multirow{3}{*}{ Uू } & 15 min before & 45 & $20,67 \pm 2,663$ & $18 * 28$ & 20,0 & \multirow{3}{*}{39,988} & \multirow{3}{*}{$0,000^{* *}$} \\
\hline & Immediately after & 45 & $23,60 \pm 2,240$ & $18 * 32$ & 24,0 & & \\
\hline & $15 \mathrm{~min}$ after & 45 & $21,33 \pm 2,449$ & $18 * 30$ & 22,0 & & \\
\hline \multirow{3}{*}{ 葛 } & 15 min before & 45 & $22,09 \pm 2,695$ & $18 * 28$ & 22,0 & \multirow{3}{*}{18,776} & \multirow{3}{*}{$0,000^{* *}$} \\
\hline & Immediately after & 45 & $23,69 \pm 2,372$ & $20 * 30$ & 24,0 & & \\
\hline & 15 min after & 45 & $22,89 \pm 1,837$ & $18 * 28$ & 24,0 & & \\
\hline \multicolumn{2}{|c|}{ Systolic blood pressure } & $\mathrm{n}$ & Mean \pm SD & Min. * Max. & Median & $\chi^{2}$ & $\mathrm{p}^{\mathrm{a}}$ \\
\hline \multirow{3}{*}{$\begin{array}{l}\tilde{\tilde{n}} \\
\tilde{\tilde{U}}\end{array}$} & 15 min before & 45 & $123,33 \pm 17,189$ & $100 * 150$ & 130,0 & \multirow{3}{*}{35,095} & \multirow{3}{*}{$0,000^{* *}$} \\
\hline & Immediately after & 45 & $128,00 \pm 14,554$ & $100 * 150$ & 130,0 & & \\
\hline & 15 min after & 45 & $119,11 \pm 15,199$ & $100 * 150$ & 120,0 & & \\
\hline \multirow{3}{*}{$\begin{array}{l}\bar{e} \\
\dot{\Xi} \\
\dot{\Xi}\end{array}$} & $15 \mathrm{~min}$ before & 45 & $122,89 \pm 17,271$ & $100 * 150$ & 120,0 & \multirow{3}{*}{20,595} & \multirow{3}{*}{$0,000^{* *}$} \\
\hline & Immediately after & 45 & $128,44 \pm 14,609$ & $100 * 150$ & 130,0 & & \\
\hline & 15 min after & 45 & $128,67 \pm 16,597$ & $100 * 150$ & 130,0 & & \\
\hline \multicolumn{2}{|c|}{ Diastolic blood pressure } & $\mathrm{n}$ & Mean \pm SD & Min. * Max. & Median & $\chi^{2}$ & $\mathrm{p}^{\mathrm{a}}$ \\
\hline \multirow{3}{*}{ נֶ. } & $15 \mathrm{~min}$ before & 45 & $71,56 \pm 8,516$ & $60 * 90$ & 70,0 & \multirow{3}{*}{8,234} & \multirow{3}{*}{$0,016^{*}$} \\
\hline & Immediately after & 45 & $74,67 \pm 7,261$ & $60 * 90$ & 70,0 & & \\
\hline & 15 min after & 45 & $72,22 \pm 6,704$ & $60 * 90$ & 70,0 & & \\
\hline \multirow{3}{*}{$\overline{\dot{E}}$} & 15 min before & 45 & $74,44 \pm 8,134$ & $60 * 90$ & 70,0 & \multirow{3}{*}{14,574} & \multirow{3}{*}{$0,001^{* *}$} \\
\hline & Immediately after & 45 & $79,33 \pm 7,198$ & $60 * 90$ & 80,0 & & \\
\hline & 15 min after & 45 & $76,67 \pm 7,687$ & $60 * 90$ & 80,0 & & \\
\hline
\end{tabular}

Table 6 indicates the mean, standard deviation, minimum, maximum and median values, and the results of Friedman test associated with the data for pulse, respiration and blood pressure evaluated 15 minutes before drain removal, immediately after the drain removal and 15 minutes after this procedure in both the case and control groups. In the case group, the pulse values determined immediately after the procedures were significantly higher than those determined before the procedure, and 15 minutes afterwards $(\mathrm{p}<0.01)$. A significant difference was not detected in the control group $(p>0.05)$. In the case and control groups, the respiratory rate measured immediately after the procedure was found to be significantly higher than those measured 15 minutes before and 15 minutes after the procedure $(\mathrm{p}<0.01)$. In the case group, systolic blood pressure was found to be at the highest level immediately after the procedure, and at the lowest level 15 minutes after the procedure; this difference was statistically significant $(\mathrm{p}<0.01)$. In the control group, systolic blood pressure measured 15 minutes before the procedure was significantly lower compared to those measured immediately after the procedure and 15 minutes afterwards $(\mathrm{p}<0.01)$. In both the case and control groups, diastolic blood pressure measured immediately after the procedures were significantly higher compared to the values assessed 15 minutes before and 15 minutes after the procedure $(p<0.05 ; p<0.01)$.

\section{Discussion}

Although the term pain is difficult to define, it negatively affects an individuals daily life, quality of life, physiology and psychosocial status (Arslan and Çelebioğlu 2004 , Özer et al. 2006). Post-operative pain is shown to be the most common problem encountered by millions of people undergoing procedures every year (Arslan and Çelebioğlu 2004, Kırdemir and Özorak 2011). Post-operative pain is associated with the development of complications related to many systems and these complications lead to the prolongation of the patient's recovery phase (Aktan 2004, Çelik 2013). The therapeutic role of the surgical nurse is key for the evaluation of post-operative pain and pain relief (Iş1kl1 2009). Previously, treatment with drugs has been the therapy used in the presence of pain, and it has been established that non-pharmacological methods are used less frequently (Ay and Alper 2010, Çelik 2013). Non-pharmacological methods are applied when analgesics are not used, if the effects of analgesics are insufficient, and for producing a synergic effect in combination with drugs. They are also used alone (Arslan and Çelebioğlu 2004).

In the present study; the age, educational status and the presence of a chronic disease, which are included in the sociodemographic characteristics, were not found to significantly affect the perception of pain (Kurdemir and Özorak 2011). Reported that there is no correlation between age and pressure pain threshold (Kirdemir and Özorak 2011). In another study, age was not considered to affect the degree of pain in case and control groups (Arslan et al. 2012).

In the literature, it has been stated that gender has an association with pain, and women complain about pain more frequently than men and use analgesic drugs more regularly (Önder, Koçıa et al. 2002 , Kirdemir and Özorak 2011). In the present study, women in the control group had higher VPS (pain) values prior to the procedure, and this result is similar with those in the literature. In our study, the value of VPS (pain) evaluated 15 minutes before drain removal was higher in the case group patients than those in the control group, while the VPS values determined immediately after the procedure and 15 minutes later decreased significantly compared 
to the control group. As a result we can conclude that the muscle relaxation exercise and music therapy might have a significant effect in decreasing the level of pain.

We have reviewed several studies that parallel our results, indicating that the music therapy is effective in decreasing pain intensity. Çiftçi (2011) has investigated the effects of music on comfort, anxiety and pain in patients diagnosed with a cerebrovascular event, who were hospitalized in the intensive care unit. In this study, the mean VPS pain score was found to be 2.3 at the initial stage when the patients were not listening to music, and the pain level was found to have decreased gradually and significantly after the patients had listened to music (VPS: 0.7 ). The authors have concluded that music therapy was positively effective in decreasing the patients' pain (Çiftçi 2011). Topçu (2008) conducted a study with 60 patients who underwent upper abdominal surgical interventions, and taught them relaxation techniques to evaluate the effects of these exercises on pain. In this study, the pain intensities evaluated immediately after the relaxation exercise and 15 minutes later were found to be significantly lower than that those evaluated prior to the exercise (Topçu 2008). Tse et al. (2005) investigated the effects of listening to music following nasal surgery on the pain level (using VPS) and hemodynamic variables of the patients. The authors reported that the values relating to pain, diastolic blood pressure and heart rate decreased in the patients, and concluded that the music therapy was an effective nonpharmacological method (Tse, Chan, Benzie 2005). In a meta-analysis, the intensity of post-operative pain was found to decrease by $50 \%$ in patients who were given music therapy, and it was noted that these patients needed lower doses of analgesics compared to those who were not given music therapy (Cepeda et al. 2006). Ajorpaz et al. (2014) evaluated pain in 60 patients who underwent open heart surgery, by giving them music therapy; in this study, the mean VPS score following music therapy was found to have decreased by nearly $50 \%$ compared to the values assessed prior to music therapy in the case group, and it was concluded that music therapy was an effective complementary method in decreasing post-operative pain (Ajorpaz et al. 2014).

In the present study, the music therapy and muscle relaxation exercises were determined to have positive effects on vital signs in the case group. Body temperatures in the case group were found to be lower for all measurements, compared to those of the control group; nevertheless, none of the patients in either group had a body temperature higher than $37.7^{\circ} \mathrm{C}$. Pulse rates did not differ between the groups and mean respiratory rates were found to be lower in the case group. The mean values of blood pressure following drain removal were found to be lower in the case group compared to the control group.

Some of the studies supporting the results of the present study are summarized, as follows: In the study of Çiftçi (2011), the mean values of diastolic blood pressure, heart rate and respiratory rate did not differ significantly between the periods of listening to music and not listening to music, while the systolic blood pressure decreased significantly in the patients after they had listened to music (Çiftci 2011). Araç (2012) evaluated the effect of music therapy on the vital signs of patients in surgical intensive care, and determined that the high mean pulse values decreased and approached normal values following music therapy; this result was statistically significant (Araç 2012). In the study of Arıoğlu (2012), systolic blood pressure increased slightly in both groups immediately after the drain removal, and declined, returning to its initial level in the case group, 15 minutes after the procedure (Arığlu 2012).

\section{Conclusion And Suggestions}

This study was conducted to evaluate the effect of music therapy and muscle relaxation exercises given prior to drain removal on pain and psychometric variables. The results revealed that the muscle relaxation exercises and music therapy were effective on some psychometric variables, and decreased the sensation of pain. In conclusion, we consider that muscle relaxation exercises and music therapy should be applied prior to drain removal procedures, as effective non-pharmacological methods for pain control, and health personnel should have sufficient expertise regarding the importance of non-pharmacological methods in pain management, and further studies should be conducted on the efficacy of non-pharmacological methods and their use in drainage procedures.

\section{Acknowledgements}

We thank Prof. Dr. Emin Sami Gürleyik and Hacer Ak Ergün, the nurses responsible for General Surgery, for their help in data collection.

\section{References}

[1]. Ajorpaz NM, Mohammadi A, Najaran H, Khazaei S (2014). Effect of Music on Postoperative Pain in Patients Under Open Heart Surgery, Nurs Midwifery Stud. September; 3(3): e20213.

[2]. Akdovan T (1999). Assessment of Pain in Healthy Newborns, Examination of the Effect of Teeth and Teeth, Marmara University Institute of Health Sciences Child Health and Diseases Nursing with an MA, MS Thesis, İstanbul.

[3]. Aktan Ö (2004). Postoperative Care. Sayek I (Eds), Basic Surgery. 3. Print.Ankara: Güneş bookstore. P.121.

[4]. Apfelbaum JL, Chen C, Mehta SS, Gan TJ (2003). Postoperative pain experience: results from a national survey suggest postoperative pain continues to be undermanaged. Anesth Analg; 97: 534- 40.

[5]. Araç B (2012). The Effect Of On Vital Sıgns Of Patients In Surgıcal Intensıve Care Unıt. İnönü University Health Sciences Institute Surgical Nursing Master Thesis, Malatya. 
[6]. Arığlu B (2012). The Effect of Progressive Muscle Relaxation Exercise on Pain before the Removal of the Chest Tube. Cukurova University Health Sciences Institute Nursing Department, Graduate Thesis.

[7]. Arslan K, Erenoğlu B, Atay A, Köksal H, Doğru O (2012). Effect of Drain Localization on Postoperative Pain in Laparoscopic Cholecystectomy: Prospective, Randomized and Controlled Study. EJSS; 3(3): 86- 91.

[8]. Arslan S, Çelebioğlu A (2004). Postoperative Pain Management and Alternative Practices, International Journal of Human Sciences ISSN: 1303- 5134.

[9]. Aslan EF (2002). Pain Assessment Methods. Cumhuriyet University Nursing School Magazine; 6 (1): 9- 16.

[10]. Aslan EF (2011). Pain Internal and Surgical Care. Nobel Medical Bookstore; 145-163.

[11]. Aslan F, Özyalçın S (2010) . The Nurse's Role In Pain Control. 2. National Congress of nurses and midwives. Antalya ,October : $103-104$.

[12]. Ay F, Alper ŞE (2010). Approaches taken by nurses in treating postoperative pain, Pain; 22(1): 21- 29 .

[13]. Bektaş YY (2005). Preemptive lornoxicam and rofekoksib in patients of total abdominal hysterectomy a double-blind comparison of the effect on postoperative morphine consumption in a way. Şișli etfal training and research hospital, II. Anesthesiology and reanimation Clinic Expertise Thesis. Istanbul.

[14]. Bennett MI, Bagnall AM, José Closs S (2009). How effective are patient-based educational interventions in the management of cancer pain? Systematic review and meta-analysis. Pain. Jun; 143(3): 192-9.

[15]. Bonica JJ (1990). General considerations of chronic pain. Philadelphia: Lea \& Febiger.

[16]. Bradt J, Dileo C. Music therapy for end-of-life care. Cochrane Database Syst Rev 2010 Jan 20;(1): CD007169.

[17]. Browett JP, Gibbs AN, Copeland SA, Deliss LJ (1978). The use of suction drainage in the operation of meniscectomy. J Bone Joint Surg Br. 60-B: 516-519.

[18]. Cepeda MS, Carr DB, Lau J, Alvarez H (2006). Music for pain relief. Cochrane Database Syst Rev. Apr 19;(2): CD004843.

[19]. Chen S, Li J, Lix and Xul (2005). Effects of vacuum assisted closure on wound micro-circulation: An experimental study. Asian J. Surg. 28; 211

[20]. Cordosi RJ, Drake J, Holmes S, Tebes SJ, Hoffman MS, Fiorica JV, Roberts WS, Grendys EC (2006). Subcutaneous management of vertical incisions with 3 or more centimeters of subcutaneous fat. Am. J. Obstet Gynecol; 195 (2): $607-614$

[21]. Çelik S (2013). PAIN LEVELS OF THE PATIENTS AFTER 24-48 HOURS FROM ABDOMINAL SURGERY AND APPLIED NURSING INTERVENTIONS , Gümüşhane University Journal of Health Sciences:; 2(3).

[22]. Çiftçi H (2011). Music comfort of the patients hospitalized in the intensive care unit with a diagnosis of cerebrovascular accident, investigation of the effect of anxiety and pain, Çukurova University, Institute of Medical Sciences, Nursing Department Master's thesis, Adana.

[23]. deBeer Jde V, Winemaker MJ, Donnelly GA, et al. (2005). Efficacy and safety of controlled release oxycodone and standard therapies for post-operative pain after knee or hip replacement. Can J Surg; 48:277.

[24]. Durai R, Mouwnah A, Ng PCH (2009). Use of drains in surgery; a review. The Journal of Perioperative Practice; 19(6): 180- 6.

[25]. Durai R, Ng PC (2010). Surgical vacuum drains, types, uses and complications. AORN J; 91:266- 271.

[26]. Erdine S, Yücel A (1993). New developments in the control of postoperative pain. Journal Of Anaesthesia; 39:1(2)

[27]. Erdine, S. (Ed.). (2003). Pain syndromes and their treatment. Sanovel Pharmaceutical Industry Publisher. İstanbul.

[28]. Gengross H, Engler V (1989). Gravity drainage versus suction drainage: an experimental and clinical study. Unfollchirurg; 92: 3742

[29]. Gift AG, Bolgiano CS, Cunninghom J (1991). Sensations during chest tube removal. Heart Lung; 20: $131-137$.

[30]. Howard VA, Thurber FW (1998). The interpretation of infant pain physiological and behavioral. Indicators used by NICU nurses. J Pediatr Nurs; 20:853-860.

[31]. http://www.e-kutuphane.teb.org.tr/pdf/raporlar/agri_v_akilci_analje/6.pdf. Date of Access : 01.11.2016.

[32]. http://www.guideline.gov/content.aspx?id=23897. Date of Access: 01.12.2016.

[33]. Işıklı GA (2009). Determination Of Patıent's Experıences Havıng a Closed Underwater Draın. Trakya University Institute Of Health Sciences, Nursing Graduate Program, Edirne.

[34]. Kurdemir P, Özorak Ö (2011). Can Postoperative Pain and Analgesic Need be Predicted in Preoperative Period? J Med Sci. 31 (4); 951- 9.

[35]. Kocaman G (1994). Nursing Approaches To Pain. Saray Medical Bookstore, İzmir.

[36]. Luckmann J, Sorenson KC (1996). Medical Surgical Nursing, Fourth Edition, WB Saunders Company, Phiadelphia.

[37]. Maddox JM, Anderson JA, Plews D, Ludlom CA (2005). Management of acquired von Willebrand's syndrome in a patient requiring major surgery. Haemophilia; 11: 633- 637.

[38]. Mahfouz I $I^{1}$, Asali F, Johnson N, More V, Sayer T, Phillips C (2011). Pain scores during surgical drains removal after obstetrics and gynaecological surgery. J Obstet Gynaecol. 2011 May; 31(4): 335-7.

[39]. Makama JG, Ameh EA (2008). Surgical drains: what the resident needs to know. Jul- Aug; 17(3): $244-50$.

[40]. Memon MA, Memon MI, Donohue JH (2001). Abdominal Drains: a brief historical review. Ir Med J. Jun; 94 (6): $164-166$

[41]. Merskey H, Bogduk N, et al. (1986) Classification of chronic pain: Description of chronic pain syndromes and definition of pain terms. IASP subcommittee on Taxonomy; 3:1- 226.

[42]. Önder E, Koçıa O ve ark. (2002). Individuals over the age of 18 living in the region Yunus Emre health pain medication use, and determination of some information on this, http://www.thb.hacettepe.edu.tr/arsiv/2002/sayi_1/baslik2.pdf.

[43]. Özcan T (2000). Neck and orofacial pain the pain . İstanbul: Nobel Medical Bookstore.

[44]. Özer S, Akyürek B, Başbakkal Z (2006). Investigation of nurses' pain related knowledge, attitude and clinical decision making skills. Pain, 18(4): 36-44.

[45]. Özveren H. (2011). Non-Pharmacological Methods at Pain Management. Hacettepe University Faculty of Health Sciences Nursing Journal; 83- 92.

[46]. Paley CA, Johnson MI, Tashani OA, Bagnall AM. Acupuncture for cancer pain in adults. Cochrane Database Syst Rev. 2011 Jan 19;(1): CD007753

[47]. Pearl ML, Rayburn WF (2004). Choosing abdominal incision and closure techniques: a review. J, Reprod Med. Aug, 49(8): 662670.

[48]. Pittler MH, Ernst E. Complementary therapies for neuropathic and neuralgic pain: systematic review. Clin J Pain. 2008 Oct; 24(8): 731-3.

[49]. Samaraee AA, Rhind G, Saleh U, Bhattacharya V (2010). Factors contributing to poor post-operative abdominal pain management in adult patients: a review. The Surgeon, 8 (3);151-158.

[50]. Schoretsanitis G, Melissas J, Sanidas E, Christodoulakis M, Vlachonikolis JG, Tsiftsis DD (1998) Does draining the neck affect morbidity following thyroid surgery? Am Surg. 1998 Aug; 64(8): 778-80. 
[51]. Serpell M (2006). Anatomy, physiology and pharmacology of pain. Basic Science, Surgery; 24(10); 349-352.

[52]. Sternbach, R. A. 1968. Pain: a psychophysiological analysis. New York: Academic Press

[53]. Sondak VK, Mortan DL(1985). A simple, inexpensive technique for clearing obstructed closed suction drainage catheters. Surg Gynecol Obstet . 161: 594- 596.

[54]. Sullivan B (2008). Nursing management of patients with a chest drain. Br J Nurs. Mar 27- Apr 9; 17(6): 388-93.

[55]. Summers S (2000). Evidence-Based practice part 1: pain definitions, pathophysiologic mechanisms and theories. J Peri Anesthesia Nurs; $15(5): 357-365$

[56]. Sütekin E (2005). Pain in the jaw and facial region. EGE University School of Dentistry oral \& Maxillofacial Surgery, Department of thesis, İzmir.

[57]. Topçu YS (2008). The Effect Of Relaxatıon Technıques That Taught By The Nurses On Pain Control In Patients With Upper Abdomınal Surgery. Trakya University Institute Of Health Sciences, Master Of Science In Nursing, Edirne.

[58]. Tse MM, Chan MF, Benzie IF (2005). The effect of music therapy on postoperative pain, heart rate, systolic blood pressure and analgesic use following nasal surgery. J Pain Palliat Care Pharmac other; 19(3): 21-9.

[59]. Tsujinaka S, Kawamura YJ, Konishi F, et al. (2008). Pelvic drainage for anterior resection revisited: use of drains in anastomotic leaks. ANZ S Surg. Jun; 78(6): 461-5.

[60]. Tzarnas CD (2006). A simple device to reliably facilitate the stripping of a closed- suction drainage tube. Plast Reconstr Surg; 117 : 2113- 2114.

[61]. Walker J (2007). Patient Preparation for safe removal of surgical drains. Nursing Standard; 21(49): 39- 41.

[62]. Walsh DM, Howe TE, Johnson MI, Sluka KA (2009). Transcutaneous electrical nerve stimulation for acute pain. Cochrane Database Syst Rev. Apr 15;(2): CD006142.

[63]. Watcha MF, Issioui T, Klein KW, White PF (2003). Costs and effectiveness of rofecoxib, celecoxib, and acetaminophen for preventing pain after ambulatory otolaryngologic surgery. Anesth Analg; 96: 987.

[64]. Willens J S. Pain Management. In: Smeltzer JC, Bare BG (Eds). Brunner \& Suddorth's Textbook of Medical Surgical Nursing. 10th Ed. Philadelphia. Lippincott William \&Wilkins: 2006; 216-248.

[65]. World Health Organization Cancer Pain Relief. Geneva: World Health Organization, 1986.

[66]. https://en.wikipedia.org/wiki/Margo_McCaffery). 